Short Communication

\title{
Corrosion Resistance of Nickel-Phosphorus/Nano-ZnO Composite Multilayer Coating Electrodeposited on Carbon Steel in Acidic Chloride Environments
}

\author{
Nan Jiang, Yan Liu*, Xiaonan Yu, Haobo Zhang, Mingming Wang \\ North China University of Science and Technology, Tangshan, China \\ *E-mail: liuyansci@ sina.com
}

doi: $10.20964 / 2020.06 .50$

Received: 4 February 2020/ Accepted: 26 March 2020 / Published: 10 May 2020

\begin{abstract}
In this study, a multilayer nickel-phosphorus (Ni-P)/nano-ZnO composite multilayer coating electrodeposited on carbon steel (CS) substrate was investigated for higher corrosion resistance and surface hardness. Scanning electron microscopy, X-ray diffraction and energy-dispersive X-ray spectroscopy analysis were employed to consider the microstructure, surface morphology and composition of the samples. The polarization and electrochemical impedance spectroscopy (EIS) tests were used to measure the corrosion resistance of the Ni-P/n-ZnOcomposite multilayer coated CS and its heat treatment in acidic chloride environment. The results showed that the multilayer $\mathrm{ZnO}$ nanostructures and Ni-P coatings on CS substrates indicated an excellent corrosion protection behavior because of the ceramic protective barrier and higher hardness on the metal surface. The corrosion protection of heat-treated $\mathrm{Ni}-\mathrm{P} / \mathrm{n}-\mathrm{ZnO}$ coated CS revealed a lower $\mathrm{I}_{\text {corr }}$ and higher $\mathrm{E}_{\text {corr }}$ than the other samples which can be related to the considerable enhancement of hardness in the Ni-P/nZnOcomposite multilayer coating by heat treatment.
\end{abstract}

Keywords: Electrodeposition; Multilayer coating; Carbon steel; Heat treatment; Corrosion behavior

\section{$\underline{\text { FULL TEXT }}$}

(C) 2020 The Authors. Published by ESG (www.electrochemsci.org). This article is an open access article distributed under the terms and conditions of the Creative Commons Attribution license (http://creativecommons.org/licenses/by/4.0/). 